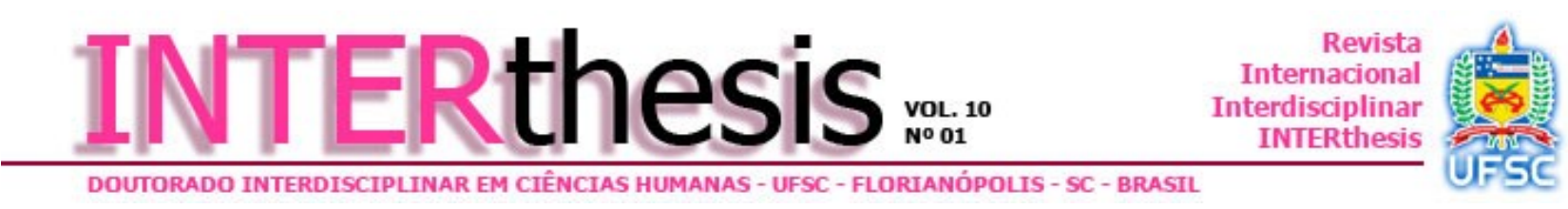

\title{
MUJERES UNIVERSITARIAS, MILITANCIA Y VIDA COTIDIANA EN TUCUMÁN, 1969-1972
}

\author{
Silvia Gabriela Nassif ${ }^{1}$ \\ Verónica Alicia Ovejero ${ }^{2}$
}

\section{Resumen:}

El presente trabajo constituye una aproximación a las diferentes manifestaciones de la militancia estudiantil de mujeres tucumanas y el impacto de la misma en su vida cotidiana durante el período 1969-1972, momento en el que se desarrollaban en la provincia importantes levantamientos, en sintonía con el ciclo de protestas a nivel nacional, protagonizado por amplios sectores populares contra la autodenominada "Revolución Argentina". Nuestra primera hipótesis sostiene que en este momento irrumpieron masivamente las mujeres en la militancia estudiantil poniendo de manifiesto un salto cualitativo respecto a períodos anteriores. Estos factores, la mayor presencia femenina en la universidad y su creciente participación en la política estudiantil, produjeron importantes transformaciones en su vida cotidiana. Asimismo, el acercamiento de las mujeres a la militancia no estuvo determinado a priori por su condición femenina sino por la adhesión a reivindicaciones políticas y sociales generales. Sin embargo, quizás a través de aquella práctica militante tomaron conciencia de las objetivas asimetrías con el género masculino. Si bien en el último tiempo asistimos a la proliferación de distintos estudios respecto a la temática de las mujeres, las fuentes continúan siendo fragmentarias y escasas. En este sentido, esperamos que nuestro trabajo represente un aporte más a la historia de las mujeres, así como a la historia de nuestra provincia. El marco teórico utilizado recoge los aportes de la psicología social pichoniana. A su vez, apelamos al uso de la historia oral a partir de la recolección de diversos testimonios de mujeres y hombres militantes durante el período mencionado.

Palabras-clave: Mujeres. Universidad. Dictadura. Militancia. Vida cotidiana.

\section{Introducción}

\footnotetext{
1 Professora e graduada em história pela Universidade Nacional de Tucumán, UNT, Tucumán, Argentina. Investigadora do Instituto de Investigações Históricas Dr. Ramón Leoni Pinto da UNT. Bolsista de doutorado do Conselho Nacional de Investigações Científicas e Técnicas CONICET. Email: nassifsilvia@gmail.com

${ }^{2}$ Graduada em história pela Universidade Nacional de Tucumán, UNT, Tucumán, Argentina. Investigadora do Instituto de Investigações Históricas Dr. Ramón Leoni Pinto da UNT. Bolsista de doutorado do Conselho Nacional de Investigações Científicas e Técnicas CONICET. E-mail: veroovejero7@gmail.com
} 
Durante la última década han proliferado trabajos que abordan la problemática sobre las mujeres y la militancia a fines de los sesenta y comienzos de los setenta. Muchas de estas investigaciones se han enfocado en el estudio de militantes mujeres, miembros de organizaciones armadas o guerrilleras de izquierda, representando un importante aporte a la temática. ${ }^{3}$

Con este trabajo nos propusimos indagar acerca de la militancia de las mujeres en la Universidad Nacional de Tucumán (UNT), centrándonos en aquellas que formaron parte de agrupaciones políticas de izquierda -no guerrilleras- $y$ analizar las implicancias de esta militancia en su vida cotidiana. Para ello hemos recogido los testimonios de dirigentes estudiantiles de aquel período, mujeres y varones. En este sentido nos resultó interesante consignar no sólo la vivencia de las mujeres y sus reflexiones sobre su papel en aquel proceso, sino también cómo fue percibida esta militancia por sus compañeros, tanto en el interior de las agrupaciones estudiantiles como en los centros y federaciones estudiantiles y también en la lucha en las calles durante los levantamientos populares.

Nuestra primera hipótesis sostiene que en este momento irrumpieron masivamente las mujeres en la militancia estudiantil poniendo de manifiesto un salto cualitativo respecto a períodos anteriores. Estos dos factores: la mayor presencia femenina en la universidad y su creciente participación en la política estudiantil, produjeron importantes transformaciones en su vida cotidiana. Asimismo, el acercamiento de las mujeres a la militancia no estuvo determinado a priori por su condición femenina sino por la adhesión a reivindicaciones políticas y sociales generales. Sin embargo, fue aquella práctica militante la que contribuyó a la toma de conciencia sobre las objetivas asimetrías con el género masculino.

Tomamos el caso de cuatro mujeres tucumanas que fueron militantes estudiantiles durante su vida universitaria, con una activa participación en los centros de estudiantes, y que en la actualidad mantienen un fuerte compromiso en el ámbito político, manifiesto en actividades estrechamente vinculadas a la cuestión de género. ${ }^{4}$

\footnotetext{
${ }^{3}$ Para la elaboración de este trabajo sirvieron como guías conceptuales principalmente los trabajos de (GARRIDO; SCHWARTZ, 2005). (OBERTI; PITTALUGA, 2006, p. 38-164).

${ }^{4}$ En la actualidad ellas participan de distintas organizaciones, ya sea como miembro del Centro de Estudios Históricos Interdisciplinarios sobre las mujeres (CEHIM) de la Facultad de Filosofía y Letras de la UNT, la Casa de las Mujeres Norma Nassif, los Encuentros Nacionales de Mujeres, entre otros.
} 
El presente trabajo se enmarca en la crítica de la vida cotidiana desde un abordaje propuesto por la psicología social pichoniana, entendida como el análisis de las formas en que cada organización social concreta desarrolla el inter-juego entre las necesidades de los sujetos comprometidos en ella y las satisfacciones, metas y conductas sociales vincularmente disponibles, pautadas para esas necesidades. Resulta necesario advertir que la vida cotidiana no es una sola, pero todas están integradas en una organización que las comprende. Así, al hablar de vida cotidiana aludimos a varias vidas cotidianas. El modo de vivir de los hombres y mujeres muchas veces se transforma en un mecanismo irreflexivo y no consciente de acción. Se aceptan los hechos como parte de un todo conocido, autoevidente, como lo que simplemente es. Se mitifica lo cotidiano a partir de presentarlo como un orden natural, preestablecido e inmodificable. Este mecanismo se conoce como "naturalización" -herramienta muy utilizada por la ideología dominante-. ${ }^{5}$ Desde este enfoque nuestro objetivo responde a la necesidad de desnaturalizar el rol que socialmente nos es asignado a las mujeres, indagando para ello sobre un aspecto de la vida cotidiana poco conocido, como la militancia en el ámbito universitario.

Asimismo, hemos utilizado la historia oral como una herramienta imprescindible en la construcción de nuestro marco teórico, recurriendo a la técnica de entrevistas semi-estructuradas para recoger los testimonios de mujeres y hombres, dirigentes estudiantiles de las décadas del '60 y comienzos de los '70.

\section{La "revolución argentina" y Tucumán}

El período que nos proponemos abordar se introduce en un proceso más amplio, el de la dictadura autodenominada "Revolución Argentina". El 28 de junio de 1966, Arturo Humberto Illia fue destituido de la presidencia de la Nación por el general Juan Carlos Onganía. El peronismo continuaba proscripto. Desde el exilio, su líder Juan Domingo Perón llamó a su movimiento a "desensillar hasta que aclare". Esto generó un ambiente de confusión y de diversas expectativas, particularmente entre los obreros.

Dos meses más tarde, el 21 de agosto de 1966 José Néstor Salimei -ministro de Economía de Onganía-, mediante decreto 16.926, anunció el cierre y

\footnotetext{
${ }^{5}$ Respecto al concepto de crítica de la vida cotidiana trabajamos con: (PICHON, 1969; QUIROGA, 1998; QUIROGA; RACEDO, 1990).
}

R. Inter. Interdisc. INTERthesis, Florianópolis, v.10, n.1, p. 109-130, Jan./Jul. 2013 
desmantelamiento de 7 fábricas azucareras y la reducción de producción de azúcar para la provincia de Tucumán. Estas medidas generaron resistencia por parte del pueblo, teniendo en cuenta que el azúcar constituía la principal actividad económica. De modo que las primeras manifestaciones se llevaron a cabo ya en los prolegómenos de la dictadura. Finalmente, el cierre de 11 de los 27 ingenios azucareros existentes hasta 1966 ocasionó un verdadero cataclismo social y económico en Tucumán. ${ }^{6}$

La situación de crisis generalizada que se vivía en la provincia repercutió directamente en el movimiento estudiantil, que a partir de sus problemáticas y reivindicaciones específicas se solidarizaron con los sectores obreros, marcando lo que podría considerarse un acercamiento significativo entre obreros y estudiantes, particularmente durante el Tucumanazo de noviembre de $1970 .^{7}$

Durante los años 1971 y 1972, se realizaron múltiples manifestaciones -la mayoría reprimidas por la policía-: tomas de ingenios, marchas de los ex obreros de ingenios hacia la capital de la provincia, protesta de los obreros ferroviarios de Tafí Viejo, ocupaciones de facultades por los estudiantes, numerosos paros docentes, entre otras.

En el desarrollo de esas luchas se manifestaban distintas tendencias políticas y proposiciones estratégicas frente al poder dictatorial: en grandes sectores populares anidaba el anhelo de la vuelta de Perón al poder, diversas corrientes políticas tradicionales apostaban a la convocatoria de elecciones generales libres y se fueron desarrollando importantes contingentes políticos que buscaban por diversos caminos un derrocamiento revolucionario de la dictadura. En este escenario se produjeron las iniciativas cada vez más resonantes de los grupos que adherían a la guerrilla urbana y rural.

Al mismo tiempo a escala nacional, aumentaba la violencia y la represión por parte de la dictadura, mientras se agudizaban las contradicciones en la dirección de la "Revolución Argentina". En ese escenario, afloraría el "Quintazo" entre el 21 y el 27 de junio de 1972, con connotaciones aún más virulentas que en el Tucumanazo

\footnotetext{
6 "Eliminaron once ingenios azucareros, empujaron a unos 250.000 tucumanos a un penoso exilio interior y 11.000 pequeños productores cañeros fueron expulsados de una actividad en la que venían desempeñándose desde hacía décadas...". (PUCCI, 2007, p. 19).

${ }_{7}$ Para un estudio de los levantamientos populares en Tucumán se puede consultar: (CRENZEL, 1997; KOTLER, 2005; NASSIF, 2012b).
} 
de 1970, movimientos que tuvieron como protagonistas a los estudiantes universitarios, entre ellos a un importante número de mujeres.

Resulta necesario destacar que este clima de radicalización política estuvo asociado con una profunda politización de la cultura. Así, "Revolución cultural" fue la categoría que muchos autores utilizaron para referirse a este período de transformaciones. Diferentes movimientos fueron los canales de expresión de la nueva generación de jóvenes de los '60. A través de un nuevo lenguaje, nuevos estilos de vida, como el representado por el flower power, se rompía con los condicionamientos que imponía la sociedad burguesa y cristiana tradicional. Nuevos términos como "liberación" aludían en simultáneo a cuestiones políticas como la liberación del dominio colonial, a la vez que también se refería a la liberación sexual; nuevos géneros musicales como el rock; nuevas estéticas teatrales como el realismo brechtiano; nuevas corrientes cinematográficas como la nouvelle vague se convirtieron en símbolos de las transformaciones profundas de la sociedad occidental. Lo político y lo cultural se enlazaban constantemente. De esa forma comenzó a consolidarse la idea de que todo era político, se leía desde Rodolfo Walsh hasta Julio Cortázar, se escuchaba desde el folclore al jazz, como así también desde los Beatles al rock nacional. A razón de esto, la juventud pasó a ser una "configuración sociocultural sospechosa" ante la mirada inquisidora del régimen. ${ }^{8}$

Asimismo, a pesar del escándalo que produciría en diversas instituciones de corte conservador, el arribo del psicoanálisis y la consolidación de la psicología social produjeron un fuerte impacto cultural y sirvieron para encarar los cambios que se estaban produciendo en la moral sexual. La mayor libertad que proponían estas transformaciones iba desde la elección del uso de la píldora anticonceptiva hasta la adopción de las minifaldas y el pelo largo, aunque el gran cambio estuvo dado por la disociación que se produjo entre sexo y procreación. Todos estos elementos producían fastidio a los sectores más conservadores de la sociedad.

\section{La universidad nacional de Tucumán y la "revolución argentina"}

\footnotetext{
${ }^{8}$ Son abundantes los estudios que analizan el clima de ideas dominante en los años '60. Para un abordaje de este clima ver (COSSE, 2010). A la vez, un análisis sobre el clima represivo en la provincia de Tucumán durante el Onganiato se puede consultar en (OVEJERO, 2011).
} 
Producto de las reformas acaecidas durante la década peronista ingresaron a la universidad sectores que antes habían estado excluidos de la misma; esto derivó en un considerable aumento de la matrícula estudiantil y también en el ingreso inusitado de mujeres a la universidad. ${ }^{9}$ Este fenómeno continuó en los años siguientes. Como sostiene Beatriz Garrido: "Entre los años 1956 - 60 se va a producir en el conjunto de la universidad un ascenso en el ingreso femenino que se irá profundizando en los años siguientes". (GARRIDO, 1999, p. 44).

Es importante también destacar que Tucumán representó un polo de desarrollo cultural en el NOA ya que además de promover el fomento de actividades culturales, había sido la primera provincia en contar con una universidad nacional en la región.

Los convulsionados años que siguieron al derrocamiento del peronismo no frenaron dicho ingreso masivo. Este proceso de masificación podría constituir uno de los elementos para comprender la radicalización de los estudiantes en la década posterior. Al mismo tiempo, durante estos años se manifestó una reformulación del lugar ocupado hasta ese momento por las mujeres en tanto y en cuanto

[...] el accionar político de las mujeres se ha visto históricamente limitado a las tareas vinculadas con lo social y asistencial, que suponen el 'estar' donde algo falta, determinando que las mujeres mismas refuercen el estereotipo de sus 'cualidades femeninas' autoexcluyéndose de los espacios de toma de decisiones, reputados como masculinos. (GARRIDO; SCHWARTZ, 2005, p 7)

Josefina Racedo, estudiante de la carrera de Psicología de la Facultad de Filosofía y Letras durante los años previos al golpe de Estado de 1966, miembro del CEFyL (Centro de Estudiantes de la Facultad de Filosofía y Letras), describe cómo vivió esa experiencia:

\begin{abstract}
Nosotros veníamos de la lucha del año '58. Muchas de nosotras, que somos de las primeras generaciones de mujeres en la universidad, jcopamos! Si bien filo había estado reservado para las chicas de Letras, de Inglés, Filosofía es un fenómeno después de los '60. Nosotros 'gozamos' de un período bastante corto, que va desde la caída de Frondizi en el '62 al '66 pero eran gobiernos elegidos con una fragilidad tremenda, acosados totalmente y que daban lugar a las luchas [...] (RACEDO, 2012).
\end{abstract}

\footnotetext{
9 "En los años del primer peronismo, la Universidad pública debió comenzar a afrontar problemas cada vez más agudos. Uno de ellos era el explosivo crecimiento de la matricula. En 1947 había 51.447 estudiantes universitarios, pero en 1955 ya ascendían a casi 140.000." (BUCHBINDER, 2005, p. 159). Sin embargo, algunos autores sostienen que junto a estas reformas, la universidad perdió parte de su autonomía y su libertad académica. Ver (PUCCI, 2012, p. 19).
} 
El arribo de la autodenominada "Revolución Argentina" se propuso entre sus objetivos clausurar dicho proceso de politización y de masificación en las universidades nacionales. Como parte de las medidas emprendidas por el nuevo gobierno, el 29 de julio de 1966, se dictó la ley 16.912 que suprimió la autonomía de las universidades nacionales. Esa misma noche la Policía Federal desalojó las Facultades de la Universidad Nacional de Buenos Aires, suceso conocido como "la noche de los bastones largos". Luego la dictadura prohibió las asociaciones estudiantiles. Estas medidas ocasionaron un gran descontento en el movimiento estudiantil, que a partir de ese momento se posicionó en contra del régimen. ${ }^{10}$

Asimismo, el régimen implementó una política de "racionalización económica" en la universidad a tono con las impuestas en la provincia de cierre de ingenios azucareros, que consistió en la ejecución de medidas "limitacionistas", tales como el intento de arancelamiento y la imposición de exámenes y cupos de ingreso, a la vez que buscó privatizar los comedores y residencias estudiantiles, servicios que anteriormente habían posibilitado a los alumnos continuar con sus estudios.

Este conjunto de disposiciones nos permite comprender que el movimiento estudiantil haya sido una de las primeras fuerzas que se opuso a las políticas de la dictadura. En Tucumán, los estudiantes portaban una importante tradición de lucha en la que las mujeres comenzaron a tener una participación más destacada. Este hecho, sumado a las condiciones particulares de la provincia, se manifestará con fuerza en los levantamientos populares conocidos como "Tucumanazos".

En este sentido, también los estudiantes llevaron a cabo distintas acciones para manifestarse en contra de las políticas de la dictadura. A mediados de 1966, en la Facultad de Filosofía y Letras, por ejemplo, los estudiantes realizaron una asamblea en la que decidieron resistir la intervención de la universidad; minutos más tarde fueron desalojados por la Policía Federal. Los estudiantes opusieron resistencia y se produjeron incidentes entre los jóvenes y las fuerzas represivas en la plaza Independencia. A su vez, se solidarizaron con el movimiento obrero y

\footnotetext{
${ }^{10}$ Es importante señalar que la década del '60 se caracterizó por la fundación de nuevas carreras en las áreas de las ciencias sociales como Sociología, Psicología y Pedagogía, entre otras, lo que hablaba de la emergencia de un conocimiento a la altura de los problemas de los nuevos tiempos, y la gran afluencia de estudiantes hacia las mismas, de una juventud que sentía la necesidad de comprometerse socialmente, no sólo desde el plano intelectual, sino también desde el plano de la acción política.
} 
participaron de distintas iniciativas como de ollas populares y de manifestaciones que emergían en los pueblos azucareros del interior. (NASSIF, 2012b, p. 103).

Resulta necesario destacar que estas acciones no se iniciaron a partir del golpe de Estado, sino que el grado de participación y politización del movimiento estudiantil fue un proceso que comenzó con anterioridad. De esta manera, podemos afirmar que, si bien existía a nivel mundial un fenómeno visible de radicalización de la juventud -destacándose el Mayo francés del '68-, el proceso tucumano presentó singularidades vinculadas a la crisis estructural en que se encontraba sumida su economía. La amplia participación del movimiento estudiantil, en el que las mujeres se destacaban no sólo en las luchas hacia el interior de los claustros, sino también en las protestas en las calles, resultó un fenómeno novedoso hacia fines de los ‘60.

Como señala la estudiante de psicología, anteriormente citada:

[...] el '66 para nosotros es un punto de llegada, no sólo un arranque, porque el golpe de Estado se produce por alguna situación y Tucumán particularmente venía siendo un foco de situaciones críticas en los distintos sectores, tanto en lo económico, (en la famosa marcha de los cañeros a principios de los '60) o con el desmantelamiento progresivo de los ingenios... Eran puntos álgidos. No sólo en el '66 comienza la debacle. (RACEDO, 2012).

Creemos que esta mirada refleja hacia donde estaban direccionadas las inquietudes que movilizaban a las jóvenes a involucrarse como militantes dentro de los acontecimientos, discusiones que giraban en torno a problemáticas sociales, en las que los problemas de las mujeres aún no eran visibilizados como una necesidad a resolver.

\section{Mujeres universitarias, vida cotidiana y militancia}

Como se señaló, la masiva participación de las mujeres en la política universitaria hacia fines de los sesenta fue un fenómeno novedoso. Este proceso abarcó diferentes ámbitos -desde la Universidad, la cultura, hasta la fábrica-, y grupos sociales, en especial aquellas mujeres provenientes de las capas medias.

El contexto en el que estas mujeres desarrollaron su militancia estuvo condicionado por una profunda crisis social y económica provincial, influenciada también por un clima propicio de ideas novedosas que alentaron la radicalización política de la juventud. Esto se puso de manifiesto de forma notoria en la vida 
cotidiana de estas mujeres, principalmente en el área del tiempo familiar. Consideramos que no resulta casual que haya sido en la familia, ya que es ésta el ámbito primario dónde se constituyen los sujetos. Para poder hablar de familia hay que situarla e indagar en sus condiciones concretas de existencia, sus formas de producción, su relación con el hábitat, su pasado, su cultura y su identidad. (QUIROGA; RACEDO, 1990, p. 15-20).

Como señala Isabella Cosse (2010) en su análisis de las transformaciones de los vínculos y relaciones entre mujeres y varones, el proceso de desarrollo y cambio de la familia hacia los años '60 llegó a configurar un modelo familiar "doméstico", que establecía la división entre la mujer ama de casa y el varón proveedor. Este modelo doméstico, basado en el compañerismo y la inequidad, se mantendría vigente las décadas subsiguientes hasta los años sesenta, momento en que la autora señala como el comienzo de una fractura producida por los cuestionamientos provenientes de una juventud culturalmente rebelde y políticamente radicalizada. (COSSE, 2010, p. 126-129). En este sentido Beatriz Garrido, quien fue militante del FAUDI (Federación de Agrupaciones Universitarias de Izquierda) para luego acercarse al peronismo revolucionario, sostiene: "[...] nunca me había planteado casarme, nunca me había planteado tener hijos, es decir para mí, mi vida estaba pensada sin el matrimonio y sin la maternidad... sin tener una conciencia feminista [...]" (GARRIDO, 2012).

La afirmación de Beatriz nos lleva a reflexionar en torno a los importantes cambios en el ámbito de la familia y de la constitución de las mujeres, ya que el sólo hecho de que una mujer se pueda pensar más allá de su función destinada a la maternidad, implicaba un salto importante en la conformación de su subjetividad. Al mismo tiempo, Beatriz destaca que su decisión de ser madre estuvo vinculada al compromiso de su pareja que se dispuso a cooperar ejerciendo las funciones antes relegadas sólo a las mujeres. Más allá de que sólo sea un caso particular, consideramos que este ejemplo puede resultar un indicador de importantes cambios en algunos sectores de la sociedad.

Por su parte, Josefina al hablar sobre su entorno familiar relata:

[...] en mi familia éramos tres hermanas, las tres en la universidad; cada una estaba comprometida militando. Yo militaba en el CEFyL, que sería la izquierda, mi hermana en el humanismo, que sería lo conservador, lo tradicional, ligado a la iglesia; y la otra hermana estaba en Medicina con los independientes. Nosotras en la familia ya éramos una muestra de cómo

R. Inter. Interdisc. INTERthesis, Florianópolis, v.10, n.1, p. 109-130, Jan./Jul. 2013 
estaban distribuidos los intereses y las necesidades de los jóvenes en una organización. [...] Muchísimos -no te digo todos- teníamos una pertenencia gremial estudiantil [...]. (RACEDO, 2012)

A la vez, el testimonio de Josefina respecto a su estructura familiar resulta una muestra particular no sólo del amplio espectro de elecciones y tendencias políticas existentes en la universidad, que iban desde el humanismo hasta el reformismo y el surgimiento de una nueva izquierda, sino también el hecho que de tres mujeres todas hayan optado por la militancia universitaria.

Respecto a cómo era la militancia de las estudiantes universitarias, encontramos similitudes acerca de las características que debía tener un militante, profundamente vinculadas al conocimiento. En ese sentido Beatriz señala:

[...] había consignas tácitas... vos tenías que leer, ser un buen estudiante porque eso te legitimaba ante tus compañeros. Entonces te podías plantar frente a un docente y argumentar que vos sos un buen estudiante pero que frente a determinadas situaciones te posicionas dentro de la militancia. Ese juego fue una constante en ese momento histórico [...] (GARRIDO, 2012).

Josefina indica de qué manera, una vez egresada y desde su rol como docente universitaria, se enfrentó a una contradicción que pudo resolver de manera no dilemática, sino integrando la lucha por las reivindicaciones políticas y sociales junto a la posibilidad de enseñar científicamente.

Para mí, en un criterio, la mejor militancia era hacer ciencia, sin haber leído publicaciones o trabajos, pero tenía esa especie de convicción de que si no había buenos científicos no íbamos a salir nunca. Entonces tenía ciertas luchas con los que 'tomaban' la facultad, porque yo quería tomar prácticos... teníamos debates (...) Hasta que me di cuenta que no servía solamente la exigencia sino entender y acompañar a los estudiantes (RACEDO, 2012).

Al indagar acerca de las repercusiones que tuvo la militancia femenina en los varones, todos los entrevistados coinciden que la misma era parte de la cotidianeidad universitaria, otorgándole distintas connotaciones. Sin embargo, partiendo de la idea de que la vida cotidiana es percibida por los hombres como parte de un orden natural, preestablecido e inmodificable, un conjunto de testimonios da cuenta de que la participación de la mujer no dejaba de ser cuestionada. En ese sentido, esgrimiendo argumentos que en apariencia iban direccionados a criticar las nuevas tendencias de la "moda" o las nuevas maneras de actuar de las mujeres consideradas poco apropiadas para una "señorita", ya sea por la vestimenta o por el 
comportamiento con los compañeros varones-, en esencia lo que verdaderamente se ponía en tela de juicio era su participación política y aquellos elementos que prefiguraban la posibilidad de que estas asuman un nuevo rol social. ${ }^{11}$ De este modo, por ejemplo, Rubén Chebaia, estudiante en esos años de la Facultad de Derecho y miembro de la agrupación Franja Morada, señala que las mujeres:

[...] empiezan a ser más lanzadas, más liberales, aparece la minifalda... que ha sido motivo de un escándalo muy pronunciado... Además en aquel entonces no era muy frecuente que una chica salga con un muchacho a conversar acerca de alguna cuestión política, ya que se entendía que era romance, aunque no sea romance [...]. (CHEBAIA, 2009).

Por su parte, Roberto Pucci, en esos años estudiante de la Facultad de Filosofía y Letras, miembro de la Agrupación Universitaria Nacional (AUN), destaca que la participación de las mujeres era importante ya que "en esos momentos se introduce además en la Argentina la noción del feminismo como algo completamente novedoso [...]" (PUCCl, 2009).

Un estudiante de la carrera de Ciencias Económicas, del Movimiento Nacional Reformista (MNR) indica que: "No estaba instalada institucionalmente la lucha por la igualdad de género, pero en la práctica, en las luchas universitarias, se daba la presencia activa de la mujer" (SUCCAR, 2009). De todos modos, Roberto Pucci, advierte que:

A decir verdad las mujeres no cubrían todavía en proporciones razonables un papel directivo, el movimiento era dirigido por hombres, había dirigentes mujeres pero eran más bien la excepción, quiero decir, las comisiones directivas de los centros eran mayoritariamente masculinas, en la FUA lo mismo, en la FUT lo mismo... En las marchas, en las protestas en la calle había mucha presencia femenina de las estudiantes universitarias [...] (PUCCI, 2009).

Resulta importante destacar del testimonio de Rosa Nassif, dirigente del CEFyL y miembro de la agrupación AUDAP- FAUDI (Agrupación Universitaria de Acción Popular - Frente de Agrupaciones Universitarias de Izquierda), la importante presencia de mujeres en el centro de estudiantes de Filosofía y Letras: "[...] nacionalmente nos hacían notar que en Tucumán se daba mucho que las mujeres

${ }^{11}$ Como sostienen GARRIDO, H. B. y SCHWARTZ, A. G., (2005, p. 7) "[...] el poder es uno de los ejes sobre el cual giran las relaciones intergenéricas; éstas están atravesadas por el poder; en ellas el poder se 'pone en acto'. Son relaciones de fuerza y del resultado de estos juegos de fuerza resultaran los posicionamientos sociales, culturales y subjetivos de cada género, visibilizándose las contradicciones en los conceptos de poder y ciudadanía". 
eran dirigentes... A nivel de las reuniones de la FUA sí se notaba mucho que eran una inmensa mayoría de varones, pero no era así en Tucumán" (NASSIF, 2012a).

Podemos observar que si bien entre los dos últimos testimonios existen dispares apreciaciones sobre el lugar ocupado por la mujer en cargos directivos, ambos coinciden en señalar que a nivel nacional la participación de las mujeres era notoriamente menor que en Tucumán.

En este sentido, el 28 de mayo de 1969, un día antes del Cordobazo, en la provincia de Tucumán, en sintonía con el auge de lucha que recorría el país, los estudiantes junto a la CGT de los Argentinos realizaron un acto en la FOTIA (Federación Obrera Tucumana de la Industria Azucarera). Es significativo que de 17 oradores sólo se encontraba una mujer, Rosa N., en representación de la Junta Ejecutiva de la Federación Universitaria Argentina (FUA) que además era estudiante. ${ }^{12}$ Respecto a este acto Rosa señala:

No me daba cuenta que fui la única mujer que hablé. En general en la Universidad, nosotros no teníamos conciencia de que había una diferencia entre los hombres y las mujeres, y menos en esa época que [...] estábamos en medio de movilizaciones, de luchas, de actos relámpago [...] estábamos siempre juntos muchachos y chicas (NASSIF, 2012a).

\section{Mujeres universitarias y militancia política}

Al analizar las motivaciones de la participación de estas mujeres en la vida militante en Tucumán podemos sostener que, en gran parte, ellas estuvieron originadas a partir de los objetivos políticos y sociales que una nueva izquierda esgrimía y por la influencia del contexto.

Las trayectorias políticas familiares muchas veces fueron puestas en tela de juicio por estas mujeres. De este modo, Beatriz nos relata:

[...] yo viví en mi infancia un discurso peronista. Pero yo era muy rebelde, le hacía muchas críticas al peronismo, sobre todo al segundo peronismo y a varias medidas que había tomado; de ahí mi acercamiento a sectores más radicalizados, más de izquierda. Pero si hay una vuelta al peronismo es desde otro lugar, cuando gana Cámpora tuve mucha comunicación con Montoneros aunque yo directamente no estaba en esos espacios [...] (GARRIDO, 2012).

\footnotetext{
${ }^{12}$ Una reconstrucción de este acto en el marco del Mayo Argentino del '69 ver (NASSIF, 2012, p. 161170).
} 
Consideramos que este testimonio da cuenta de una serie de variables en la subjetividad de una parte importante de estas jóvenes: la politización creciente que se fundía en un sentimiento de rebeldía y de libertad de elección fue lo que les posibilitó generar discursos y adherir a prácticas poco frecuentes hasta esos momentos, la mayoría de las veces sin contar con el consentimiento de sus padres.

Elisa C., en esos años estudiantes de la Facultad de Ciencias Exactas y miembro del Frente de Izquierda Popular (FIP), sostiene al respecto:

Yo venía de una familia fuertemente radical por parte de padre y más bien conservadora por parte de madre... Pero en ese momento a mí me atrajo mucho la propuesta de una izquierda nacional, justamente una mirada nacional desde la defensa de lo popular y ahí me vinculo. Primero participo directamente en el centro de estudiantes, de las marchas. También he trabajado por la unificación de los centros en la universidad. ${ }^{13}$ (ELISA, 2012). ${ }^{14}$

Como señalamos anteriormente, estas mujeres se involucraron en la política universitaria a partir de reivindicaciones sociales y políticas sin plantear necesidades relacionadas a las problemáticas de las mujeres. De este modo es válido preguntarnos para el caso argentino cuál fue la importancia de estas experiencias de luchas populares para la posterior configuración de un movimiento de mujeres en el país. Para Marta Vasallo, si las mujeres ofrecieron resistencia al planteo de la cuestión femenina como cuestión política, ello no impidió que se operaran rupturas drásticas con la educación recibida y con los roles que la familia y la sociedad les imponía. $^{15}$

Así Beatriz nos cuenta que ella se acercó al feminismo a fines de la década del '80. Mientras que señala que hacia fines de los sesenta, si bien no existía con nitidez una militancia feminista, la participación de un grupo de mujeres tucumanas fue, en algunos casos, claramente equiparable a la de los varones.

\footnotetext{
${ }^{13}$ La entrevistada se refiere al proceso de unificación de los centros de estudiantes que aglutinó en un mismo gremio estudiantil tanto a los reformistas como a los humanistas y a todas las nuevas tendencias de izquierda. De esta manera se consumó la organización de Centros Únicos de Estudiantes por facultad en la UNT.

${ }^{14} \mathrm{~A}$ pedido de la entrevistada solo utilizaremos su primer nombre.

15 "Cabría pensar aquella militancia femenina de los setenta como la forma preponderante que cobró la ruptura femenina con los roles tradicionales, imponiéndose sobre otras formas posibles ya existentes pero que no podían cobrar fuerza por razones históricas, culturales y también coyunturales: un criterio evolucionista democrático, la concientización feminista, el pacifismo." (VASALLO, 2009, p. 30-31).
} 
Cuando vos no tenés una conciencia de la discriminación no te das cuenta, vivís muchas cosas con naturalidad, pero yo creo, mirándolo en perspectiva, no porque me hubiese dado cuenta en ese momento, que en Tucumán han habido muchas dirigentes mujeres, mujeres que se paraban en las asambleas, discutiendo de igual a igual con dirigentes varones [...] te movilizaban toda una facultad... hubo muchas mujeres que tenían un trabajo militante muy bueno, quizás los varones no hacían ese trabajo... en general a las aulas a hablar a los cursos y demás iban más mujeres que varones (GARRIDO, 2012).

Este testimonio apoyaría la afirmación de Rosa respecto a la singularidad de la participación de las mujeres tucumanas, en tanto y en cuanto queda de manifiesto que se trataba de un activo. Asimismo, Beatriz destaca que implícitamente existía una división en las tareas de los militantes. De esta forma, resulta posible pensar que el rol asumido por las mujeres universitarias consistía en general en tareas fundamentales para el funcionamiento cotidiano de las organizaciones, como la prensa y la difusión, mientras que la toma de decisiones era un espacio reservado para los varones. No obstante un grupo importante de mujeres logró acceder a dichos espacios, como lo muestra el caso de la Facultad de Filosofía y Letras de la UNT, lo que podría ser un emergente del nuevo rol político que comenzaría a asumir la mujer de allí en más.

\section{La cuestión de la mujer: los casos del FIP y del PCR en Tucumán}

A comienzos de los setenta comenzaron a hacerse visibles, en el seno de algunos partidos, las reivindicaciones específicas de las mujeres. Así se conformaron organizaciones como la Unión Feminista Argentina (UFA) en el año 1970, el Movimiento de Liberación Femenina (MLF) en 1972 y más tarde la Asociación para la Liberación de la Mujer Argentina (ALMA). Algunas organizaciones de izquierda también se plantearon un acercamiento al feminismo, este es el caso de "Muchacha", del frente feminista del Partido Socialista de los Trabajadores (PST), el Movimiento Feminista Popular del FIP y el efímero Frente de mujeres del Partido Revolucionario de los Trabajadores (PRT). (ANDÚJAR, 2009, p. 12). Un ejemplo de ello nos lo transmite Elisa C., estudiante universitaria en esos años y miembro del FIP:

Hay un grupo de mujeres en Buenos Aires del partido que empieza a plantear la problemática de la discriminación de la mujer. En general desde la izquierda había un cierto rechazo por los planteos feministas. Así 
comenzamos a ver bibliografía internacional. Entonces lo que nosotros planteábamos era participación e igualdad de oportunidades. No hemos identificado la lucha nuestra tanto con aspectos como la libertad sobre tu cuerpo, etc., sino que nos hemos orientado mucho en la participación política y en la igualdad de oportunidades para trabajar (ELISA, 2012).

De este modo, Elisa relata que el FIP sirvió como punto de partida para conformar una agrupación denominada "Nosotras las Mujeres", cuya forma de reconocer las necesidades y demandas fue a través de la organización de eventos como charlas, adonde se invitaban a psicólogos, historiadores y se debatían problemáticas específicas de las mujeres. Esta experiencia trajo como consecuencia la formación de una corriente a escala nacional. Elisa describe entre sus logros que:

[...] nos aproximamos al mundo de las amas de casa, que es bastante vapuleado desde todos lados, porque hay creencias de que las amas de casa son las más reaccionarias de todas, que no quieren cambiar nada; porque en cierto sentido hay más indefensión, no tienen su independencia, su sueldo, dependen de alguien que las mantenga. $Y$ empezamos a plantear cosas que ya se conocían, pero las popularizamos, que tenían que ver con el reconocimiento de ese trabajo invisible de la casa que permite que una sociedad funcione [...] Y después se forma el sindicato de amas de casa [...] Hemos planteado un feminismo de reconocimiento de las potencialidades, de las cosas de la mujer y de la necesidad de involucrar a la mujer en la política [...] (ELISA, 2012).

Con respecto a la percepción de los varones de su agrupación sobre esta experiencia, Elisa describe que:

[...] al principio fue bastante duro, pero nosotras en Tucumán tuvimos un apoyo muy grande... todo el grupo de varones militantes fue excelente. No así en Santa Fé, Córdoba, Salta y Mendoza, que no estaban de acuerdo. Pero en Tucumán tuvimos bastante apoyo y leían con nosotras, nos conseguían bibliografía y hacíamos cursos y discusiones. (ELISA, 2012).

Asimismo, Andújar señala que las reticencias provenían también del conjunto de mujeres militantes pertenecientes a la izquierda revolucionaria:

...consideraban que la lucha contra la desigualdad y la jerarquía sexual
formaba parte de una reivindicación burguesa y era secundaria frente a la
contradicción entre capital y trabajo... por lo que no se consideraba
problemático postergar la lucha en este terreno (ANDUJAR, 2009, p. 12-13).

Sin embargo, es posible pensar que si las reivindicaciones de las estudiantes no estaban explícitamente relacionadas con la desigualdad de género, existieron prácticas concretas de distintas agrupaciones de izquierdas que comenzaron a 
dilucidar de manera incipiente los problemas específicos de las mujeres. En este sentido, Rosa indica:

[...] cuando nosotros fuimos desde la Universidad a trabajar en los ingenios, en las casas de los obreros azucareros y en las colonias [...] ahí comenzamos a ver con muchísima claridad el lugar de la mujer como un lugar subordinado. Por ejemplo, nosotros íbamos a las casas y estábamos hablando con los compañeros y las mujeres estaban por ahí paradas, o cebaban mate, traían el mate pero no se sentaban a la rueda en donde nosotros estábamos hablando, no se incluían. Inclusive en algún momento preparaban la comida y no se sentaban en la mesa (NASSIF, 2012a).

De este modo, Rosa nos cuenta que ante esta situación ellos elaboraron distintas estrategias para acercarse a las mujeres sin la mediación de los hombres: "[...] entonces empezamos a ir a las casas en momentos en que estaban las mujeres solas y nos sentábamos a hablar con ellas. O cuando estaban paradas hacíamos una cosa especial de dirigirnos a ellas y ahí sí se facilitaba [...]" (NASSIF, 2012a).

Como consecuencia de estas experiencias, en el año '71 el PCR (Partido Comunista Revolucionario) advirtió la necesidad de encarar de manera específica el problema de género. Así, designaron una responsable femenina del partido para abordar esta tarea a través de distintas instancias organizativas con el objetivo de incorporar a las mujeres a la lucha social. Así Rosa destaca:

[...] había un trabajo con las mujeres para que se incorporaran a las luchas y a partir de ahí atender a sus problemas particulares, pero que aparecían muy vinculados a los problemas domésticos: a que si tenían que salir a trabajar qué pasaba con los chicos, a que tenían que haber guarderías en las fábricas. (...) Pero por ejemplo, no había una conciencia de la violencia doméstica, eso recién aparece con mucha fuerza después de la dictadura (NASSIF, 2012a).

Ambas experiencias dan cuenta que fue a partir de la lucha social que muchas organizaciones políticas se propusieron establecer vínculos estrechos con los sectores populares, que también sufrían las consecuencias de la crisis económica y social provincial. En esta búsqueda advirtieron la situación de subordinación que las mujeres sufrían, como lo muestra el caso de las familias obreras azucareras. Desde allí comprendieron que era necesario un trabajo diferenciado para poder acercarse a ellas. Así vemos como pusieron en funcionamiento distintas instancias de organización en las que emergieron 
problemáticas específicas de las mujeres intrínsecamente relacionadas con la crisis social que las obligaba a ocupar nuevos roles afuera y adentro de su hogar.

\section{Consideraciones finales}

Como se pudo observar a lo largo del trabajo, entendemos que no se puede estudiar esta temática sin considerar la aguda crisis social, económica y política que atravesaba Tucumán en ese período, ya que ésta tiñó todos los ámbitos de la sociedad, destacándose especialmente el espacio universitario.

El arribo de la dictadura de 1966 sumado al previo proceso de masificación de la matrícula universitaria fueron los elementos que condicionaron el fenómeno de radicalización política de los jóvenes universitarios, en especial en una provincia fuertemente vapuleada por las medidas de la "Revolución Argentina".

La militancia para estas mujeres se gestó junto a un cuestionamiento a las opciones políticas familiares que se articuló con la radicalización política de la juventud y la aspiración de cambios revolucionarios del sistema social.

Al mismo tiempo, pudimos comprobar que en este período las mujeres adquirieron una mayor participación en la política estudiantil universitaria y que la misma sucedió en un contexto de profundas transformaciones de la vida cotidiana y de la estructura familiar vigente hasta ese momento. Así, la mujer comenzó a ocupar nuevos roles, antes reservados sólo a los varones. En ese sentido sus inquietudes respecto a las problemáticas políticas y sociales de la provincia la llevó a participar activamente en agrupaciones estudiantiles, en organizaciones como los centros de estudiantes y en las luchas en las calles junto a otros sectores de la sociedad. De todos modos, esto no significó la plena igualdad en la toma de decisiones, ya que los cargos de poder estuvieron predominantemente en manos de los hombres.

Como pudimos observar, para el caso tucumano, se destacó un grupo de dirigentes mujeres que ocuparon cargos de dirección. Sin embargo, este proceso generó resistencia en distintos sectores de la sociedad, que se volvieron críticos de aquellas mujeres que se involucraban en política y que a través de argumentos conservadores, referidos a las nuevas formas y estilos, como la vestimenta y el comportamiento, encubrían lo que en el fondo cuestionaban: la práctica política de las mujeres. 
Con respecto a la problemática específica de las mujeres, se señaló de qué modo para estas universitarias se volvió evidente la diferenciación de roles entre los sexos a partir de la experiencia hacia afuera de la universidad. La búsqueda de una articulación del movimiento estudiantil con las luchas de otros sectores fue una instancia necesaria para empezar a visibilizar la problemática específica de ellas como mujeres. De este modo, es posible pensar que la mirada del vínculo entre hombres y mujeres en otros sectores sociales posibilitó, en un largo proceso, que estas mujeres universitarias comprendieran que esa diferenciación atravesaba a toda la sociedad, inclusive a ellas mismas como mujeres universitarias en relación con sus compañeros y en el interior de sus familias. En ese sentido, en la actualidad las entrevistadas son partícipes de movimientos que incluyen la lucha por las reivindicaciones de género, desde diferentes abordajes.

Para concluir consideramos que, aunque la temática respecto a las condiciones de las mujeres no fue principal dentro de las organizaciones de izquierda durante esos convulsionados años, ya que las luchas estuvieron profundamente marcadas por las reivindicaciones económicas y sociales, fue esa militancia una de las causas que sirvió para visibilizar los planteos emergentes respecto a los problemas de las mujeres, actuando como un canal de expresión. Esta cuestión se profundizará en las décadas siguientes y actualmente cobra fuerza en las múltiples organizaciones de mujeres de distintas tendencias políticas. 


\title{
MULHERES UNIVERSITÁRIAS, MILITÂNCIA E VIDA COTIDIANA EM TUCUMÁN, 1969-1972
}

\section{Resumo:}

Este trabalho aborda as diferentes manifestações da militância estudantil de mulheres tucumanas e o impacto disso em suas vidas cotidianas durante o período de 1969-1972, momento em que aconteciam no estado de Tucumán importantes levantes que estavam em sintonia com os protestos que aconteciam em nível nacional, protagonizados por diversos setores populares contra a autointitulada "Revolução Argentina". Nossa primeira hipótese consiste em que nesse momento houve uma maciça entrada das mulheres na militância estudantil, o que revela um salto qualitativo em relação a períodos anteriores. Esses fatores, a maior presença feminina na universidade e seu crescente envolvimento na política estudantil, produziram importantes mudanças em suas vidas cotidianas. Além disso, a aproximação das mulheres com a militância não esteve determinada a priori por sua condição feminina, mas sim pela adesão a reinvindicações políticas e sociais gerais. No entanto, talvez através dessa prática militante tomassem consciência das objetivas assimetrias com o gênero masculino. Embora nos últimos tempos se veja uma proliferação de vários estudos sobre a temática das mulheres, as fontes continuam fragmentadas e escassas. Neste sentido, esperamos que o nosso trabalho represente mais uma contribuição para a história das mulheres, assim como para história de nosso estado. O referencial teórico utilizado perpassa as contribuições da psicologia social de pichoniana. Ainda utilizamos a história oral para coletar diversos depoimentos de mulheres e homens militantes durante o período mencionado.

Palavras-chave: Mulheres. Universidade. Ditadura. Militância. Vida cotidiana.

\section{UNIVERSITY WOMEN, ACTIVISM AND EVERYDAY LIFE IN TUCUMAN, 1969-} 1972

\begin{abstract}
:
This work approaches the different manifestations of militancy of the student women in Tucuman and the impact of it on their daily lives during the period 1969-1972, when significant rises developed in the province, in line with the cycle of protests nationwide, featuring broad popular sectors against the self-styled "Revolution Argentina". Our first hypothesis is that at this time women broke massively in student activism revealing a quantum leap over previous periods. These factors - more women in college and their increasing involvement in student politics - carried important changes in their daily lives. Also, the women approach to militancy was not determined a priori by their gender but by their adherence to general social and political demands. However, perhaps through militant practice, they became aware of the asymmetries with the male gender. While in recent times we have witnessed the proliferation of various studies regarding the subject of women, the sources of information remain fragmented and scarce. In this regard, we hope that our work represents a further contribution to the history of women and the history of our province. Our theoretical framework includes the contributions of the social psychology from Pichon Riviere. In turn, we appeal to the use of oral history from the collection of testimonies from women and men who were activists during the period.

Keywords: Women. University. Dictatorship. Militancy. Everyday life.
\end{abstract}




\section{Referencias}

ANDUJAR, Andrea. et al. (comp.) De minifaldas, militancias y revoluciones. Exploraciones sobre los 70 en la Argentina. Buenos Aires: Luxemburg, 2009.

BUCHBINDER, P. Historia de las Universidades Argentinas. Buenos Aires: Sudamericana, 2005.

CHEBAIA, Rubén. Entrevista concedida a Silvia Nassif (digital). San Miguel de Tucumán, Argentina, 15 des. 2009. Transcripta por Silvia Nassif y revisada por Verónica Ovejero. Archivo privado.

COSSE, I. Pareja, sexualidad y familia en los años sesenta. Una revolución discreta en Buenos Aires. Buenos Aires: Siglo veintiuno editores, 2010.

CRENZEL, E., El Tucumanazo. Tucumán: Universidad Nacional de Tucumán, 1997.

ELISA, C. Entrevista concedida a Silvia Nassif y Verónica Ovejero (digital). San Miguel de Tucumán, Argentina, 27 abr. 2012. Transcripta por Silvia Nassif y revisada por Verónica Ovejero. Archivo privado.

GARRIDO, Beatriz. Entrevista concedida a Silvia Nassif y Verónica Ovejero (digital). San Miguel de Tucumán, Argentina, 24 abr. 2012. Transcripta por Verónica Ovejero y revisada por Silvia Nassif. Archivo privado.

GARRIDO, H. B. Educación, Universidad y Género. Participación de las mujeres en el espacio universitario tucumano. CEHIM, Facultad Filosofía y Letras, Universidad Nacional de Tucumán, 1999.

GARRIDO, H. B.; SCHWARTZ, A. G. Las mujeres en las organizaciones armadas de los '70. Montoneros. Revista Del Centro de Estudios Históricos Interdisciplinario Sobre las Mujeres, año 2, No 2, Tucumán: Facultad de Filosofía y Letras: Universidad Nacional de Tucumán, 2005.

KOTLER, R. El Tucumanazo, los Tucumanazos (1969-1972). In: VII Congreso Encuentro Nacional y I Congreso Internacional de Historia Oral. 2005. 
NASSIF, Rosa. Entrevista concedida a Silvia Nassif y Verónica Ovejero (digital). Buenos Aires, Argentina, 13 jul. 2012a. Transcripta por Verónica Ovejero y revisada por Silvia Nassif. Archivo privado.

NASSIF, S. Tucumanazos. Una huella histórica de luchas populares 1969-1972. Tucumán: Fac. Filosofía y Letras, Universidad Nacional de Tucumán, 2012b.

OBERTI, Alejandra; PITTALUGA, Roberto. Memoria en montaje. Escrituras de la militancia y pensamiento sobre la historia. Buenos Aires: Ediciones El Cielo por Asalto, 2006.

OVEJERO, V., Censura y represión en la cultura tucumana durante el Onganiato, 1966-1970. Tesis de Lic. 2011. (inédito).

PICHON RIVIĖRE, E. Ecología, ecología humana y Psicología Social. In: Revista Temas de Psicología Social. Buenos Aires: Ediciones Cinco, 22 de noviembre de 1969.

PUCCI, R., Historia de la destrucción de una provincia. Tucumán 1966, Buenos Aires: Ediciones del Pago Chico, 2007.

PUCCI, R., Pasado y Presente de la Universidad Tucumana. historiapolitica.com, Programa Buenos Aires de Historia Política del siglo XX, Disponible en: http://historiapolitica.com/datos/biblioteca/pucci.pdf. Acceso: 27 abr. 2012.

PUCCI, Roberto. Entrevista concedida a Silvia Nassif (digital). San Miguel de Tucumán, Argentina, 07 des. 2009. Transcripta por Silvia Nassif y revisada por Verónica Ovejero. Archivo privado.

QUIROGA, A., Psicología y Crítica de la Vida Cotidiana. In: Enfoques y

Perspectivas en Psicología Social. Buenos Aires: Ediciones Cinco, 1998.

QUIROGA, A.; RACEDO, J., Crítica de la Vida Cotidiana, Buenos Aires: Ediciones Cinco, 1990.

RACEDO, Josefina. Entrevista concedida a Silvia Nassif y Verónica Ovejero (digital). San Miguel de Tucumán, Argentina, 25 abr. 2012. Transcripta por Verónica Ovejero y revisada por Silvia Nassif. Archivo privado. 
SUCCAR, Rodolfo. Entrevista concedida a Silvia Nassif (digital). San Miguel de Tucumán, Argentina, 10 may. 2009. Transcripta por Silvia Nassif y revisada por Verónica Ovejero. Archivo privado.

VASALLO, Marta. Militancia y transgresión. In: ANDUJAR, Andrea. et al. (comp.) De minifaldas, militancias y revoluciones. Exploraciones sobre los 70 en la Argentina. Buenos Aires: Luxemburg, 2009, p. 19-32.

Dossiê:

Recebido em: Março/2013

Aceito em: Maio/2013 